\section{A polymorphic DNA sequence from the terminal part of chromosome 20q [D20S26]}

\author{
François Rouyer, Albert de la Chapelle ${ }^{1}$ and \\ Jean Weissenbach * \\ Unité de recombinaison et d'expression \\ génétique, INSERM U163, CNRS LA271, Institut \\ Pasteur, 25 rue du Dr. Roux, 75724 Paris \\ Cedex 15, France and ${ }^{1}$ Department of Medical \\ Genetics, University of Helsinki, Haartmaninkatu \\ 3, 00290 Helsinki, Finland
}

Source/Description: The probe IP20K09 is a $12 \mathrm{~kb}$ Sall fragment isolated from a $\lambda$ phage obtained by screening a human genomic library with a STIR repeated element (1). The insert is subcloned in the SalI site of $\mathrm{pBS}+$ vector (Stratagene).

Polymorphism: TaqI identifies 3 alleles defined by a $5.8 \mathrm{~kb}$ fragment, a $5.4 \mathrm{~kb}$ fragment and a $3.3 \mathrm{~kb}+2.1 \mathrm{~kb}$ doublet. Several other non polymorphic fragments are also detected.

Frequency: Estimated from 46 parents of the CEPH panel.

$5.8 \mathrm{~kb}$ allele: 0.10

$5.4 \mathrm{~kb}$ allele: 0.47

$3.3+2.1 \mathrm{~kb}$ allele: 0.43

Not Polymorphic For: BamHI, BgIII, EcoRI, HindIII, MspI, PstI, RsaI, XbaI (studied in 5 unrelated individuals).

Chromosomal Localization: Localized to $20 \mathrm{q} 13.3$ by in situ hybridization and genetic linkage analysis (1).

Mendelian Inheritance: Codominant segregation observed in 20 CEPH families.

Probe Availability: The probe will be submitted to the American Tissue Culture Collection (ATCC). Until it is made available through the ATCC it can be obtained from J.Weissenbach.

Other Comments: Segregation data included in the CEPH database version 3. RFLPs are observed under normal hybridization and wash $(0.2 \times \mathrm{SSC})$ stringencies.

Acknowledgements: This work was supported by the Ministère de la Recherche (Grant 88.C.0061), the Association Française contre les Myopathies, the Sigrid Juselius Foundation, the Academy of Finland, and the Folkhälsan Institute of Genetics.

Reference: (1) Rouyer,F. et al. (1990) EMBO J. 9, 2: 505-514.

\section{A new polymorphic probe on chromosome 3p: $\lambda$ LIB45 - 82 (D3S232)}

F.Latif, G.M.Glenn, L.N.Daniel, H.Brauch, J.Delisio', K.Hampsch', M.L.Orcutt, B.Zbar and M.I.Lerman*

Source/Description: $\lambda \mathrm{LIB} 45-82$ is a $2.2 \mathrm{~kb}$ EcoRI fragment isolated from a Charon 21A human chromosome 3 library (1).

Polymorphism: MspI digestion of genomic DNA and hybridization with the probe detects a two allele polymorphism: $4.5 \mathrm{~kb}(\mathrm{M} 1)$ and 3.45/1.05 kb (M2). No constant bands were present.

Frequency: Estimated from 36 unrelated Caucasians.

M1 : 0.64

$\mathrm{M} 2: 0.36$

Not Polymorphic For: BamHI, BglII, DraI, EcoRI, HindIII, Hinfl, PvuII, RsaI and TaqI.

Chromosomal Localization: Using a somatic cell hybrid panel (2) which was based on linkage groups anchored to physically localized markers, the probe was assigned to the short arm of chromosome 3 between 3 p21 and 3pter.

Mendelian Inheritance: Mendelian inheritance has been demonstrated in two three-generation von Heppel-Lindau disease (vHL) families.

Probe Availability: Available for collaboration.

Other Comments: The probe sequences are highly conserved between human and rodent species.

References: 1. American Type Culture Collection No. 57748, National Lab ID code LA03NS02. 2. Brauch,H. et al. (1989) A somatic cell hybrid panel for physical assignment of 3p probes. Abstract, HGM10. Cytogenet. Cell Genet. 51(1-4), 968.

*To whom correspondence should be addressed at Laboratory of Immunobiology, Frederick Cancer Research Facility, NCI-NIH, Ft. Detrick, Bldg. 560, Room $12-71$, Frederick, MD 21701, USA

\footnotetext{
* To whom correspondence should be addressed
} 